\title{
A user-centred design process of new cold-protective clothing for offshore petroleum workers operating in the Barents Sea
}

\author{
Ole Petter NAESGAARD ${ }^{1 *}$, Tore Christian Bjørsvik STORHOLMEN ${ }^{1}$, \\ Øystein Nordrum WIGGEN ${ }^{1}$ and Jarl REITAN ${ }^{1}$ \\ ${ }^{1}$ SINTEF Technology and Society, Department of Health Research, Norway \\ Received July 20, 2017 and accepted October 10, 2017 \\ Published online in J-STAGE October 17, 2017
}

\begin{abstract}
Petroleum operations in the Barents Sea require personal protective clothing (PPC) to ensure the safety and performance of the workers. This paper describes the accomplishment of a user-centred design process of new PPC for offshore workers operating in this area. The user-centred design process was accomplished by mixed-methods. Insights into user needs and context of use were established by group interviews and on-the-job observations during a field-trip. The design was developed based on these insights, and refined by user feedback and participatory design. The new PPC was evaluated via field-tests and cold climate chamber tests. The insight into user needs and context of use provided useful input to the design process and contributed to tailored solutions. Providing users with clothing prototypes facilitated participatory design and iterations of design refinement. The group interviews following the final field test showed consensus of enhanced user satisfaction compared to PPC in current use. The final cold chamber test indicated that the new PPC provides sufficient thermal protection during the $60 \mathrm{~min}$ of simulated work in a wind-chill temperature of $-25^{\circ} \mathrm{C}$. Conclusion: Accomplishing a user-centred design process contributed to new PPC with enhanced user satisfaction and included relevant functional solutions.
\end{abstract}

Key words: Protective clothing, User-centred design, Participatory design, Petroleum workers, Cold exposure

\section{Introduction}

The Norwegian petroleum industry is extending its activities further north into the southwestern area of the Barents Sea. In 2016, production started at Goliat ${ }^{1,2)}$, the first offshore oil field in the Norwegian sector of the Barents Sea, and the industry is planning to perform several frontier drilling programmes in the following years. All-year-round petroleum activity in these areas involves more challenging climatic conditions than areas further south ${ }^{3,4}$. Critical

*To whom correspondence should be addressed.

E-mail: ole.petter.nasgaard@sintef.no

(C2017 National Institute of Occupational Safety and Health climatic conditions such as low sea and air temperatures, strong winds, polar nights, icing and polar lows pose major challenges to the health, safety and performance of personnel working in these areas ${ }^{5}$. Year-round operation involves air temperatures ranging from around $0^{\circ} \mathrm{C}$ to minimum temperatures that can drop to $-30^{\circ} \mathrm{C}$ in the northern and eastern regions in the winter ${ }^{3}$. These climatic conditions come in addition to other safety-challenges for personnel in the petroleum industry, which require them to use multinorm protective clothing and a range of personal protective equipment (PPE). Cold exposure has a number of adverse consequences for human performance and health, and can be a major hazard in outdoor work, especially in winter ${ }^{6}$. Exposure to cold, snow, ice, wind and darkness can lead 
to discomfort, fatigue, impaired work ability, physical performance and cognition, injuries and cold-related accidents $^{7-12)}$.

Operations in the Barents Sea requires personal protective clothing (PPC) for cold conditions to ensure the safety and performance of the workers ${ }^{5}$. The PPC in current use does not provide satisfactory protection for optimal performance in the cold ${ }^{13)}$. Thus, the industry has recommended the development of PPC tailored to the specific environmental conditions ${ }^{14)}$. Although PPC is necessary to prevent the adverse effects of cold on the body, it may have negative effects on performance, energy consumption and manual dexterity, and it limits movement and comfort due to its weight, bulkiness, stiffness and friction between clothing layers ${ }^{15-19)}$. Petroleum workers operate in a multi-risk work environment which requires them to wear a range of PPE such as helmet, protective glasses, hearing protectors, and protective gloves and boots. This equipment introduce additional compatibility issues and affect comfort and task performance ${ }^{20)}$. Comfort is important to end-users, and PPC that impairs work performance and comfort is associated with low levels of user satisfaction ${ }^{21-23)}$.

\section{User-centred design and participatory design}

Traditional development of PPC has had limited focus on involving users. Information about the users have been limited to collection of feedback from users, or worker representatives, following the introduction of new products $^{24)}$. Limited user insight is a key factor in the failure of product innovations, while involving users in the decision about what to design promotes acceptance and satisfaction of the final products ${ }^{25-27)}$. A user-centred design process develops products based on an in-depth understanding of the user needs and context of use $\mathrm{e}^{28,29)}$, and input from users is sought throughout all stages of the development process ${ }^{30)}$. Prototyping is a key activity within user-centred design. Design assumptions based on user insights can be represented in a prototype that the users can start to test, and prototyping is a process to learn from and to inform the design process ${ }^{31}$. The design can be refined based on the user feedback regarding their experience of which designs are practical and which are not. Participatory design involves a more extensive user involvement, and emphasises active co-operation between users and designers to ensure that new products meet user needs ${ }^{30)}$. It is characterized by bringing the end-users into the development environment, rather than designers entering the work situation of the users ${ }^{24}$, and involves a shift from designing for users to designing with users ${ }^{32)}$. The end-users are the experts in the details of their work situation, and this enables them to predict challenges related to the introduction of new clothing solutions ${ }^{33)}$.

\section{Evaluation}

User-centred design of PPC must balance protection, performance and comfort properties, and objective properties and subjective preferences must be considered. Practical testing including field testing and controlled wearer tests in a cold climate chamber is recommended ${ }^{34,35)}$. Realworld field testing by end-users is a vital test of the effectiveness of the design and function of the PPC. However, field testing involve limited control of the variables ${ }^{24)}$. Standardised tests in cold climate chamber can be performed which simulate realistic environmental conditions and work characteristics.

\section{Objective}

Only a limited amount of research describes the development of cold-protective clothing for workers in the petroleum industry by following a user-centred design process. Development by following this approach can contribute to reduce the negative effects of PPC. This approach involves the users in all stages of the development process, and contributes to increased user satisfaction by focusing on the preferences and needs of the end-users ${ }^{30,36}$. This paper aims to describe a user-centred design process for new PPC for petroleum workers operating on offshore installations in the Barents Sea. The process has included elements of participatory design.

The current innovation project developed a multi-layer clothing system, which includes wool base layer, two types of wool-based mid-layers (with different levels of thermal insulation) and three outer layer garments; a weatherproof outer layer including a PTFE membrane (Fig. 1), an insulated work vest and an insulated parka. The garments were designed to interface with one another to ensure good compatibility and total protection. The project was accomplished by a multi-disciplinary research and development team (R\&D team) with expertise in design, design research and human physiology, in close collaboration with industrial partners involved in manufacturing of PPC and employers of petroleum workers.

\section{Methods}

The project followed an iterative user-centred design process, in which close attention was paid to the user needs at each stage of the design process. The process involved 


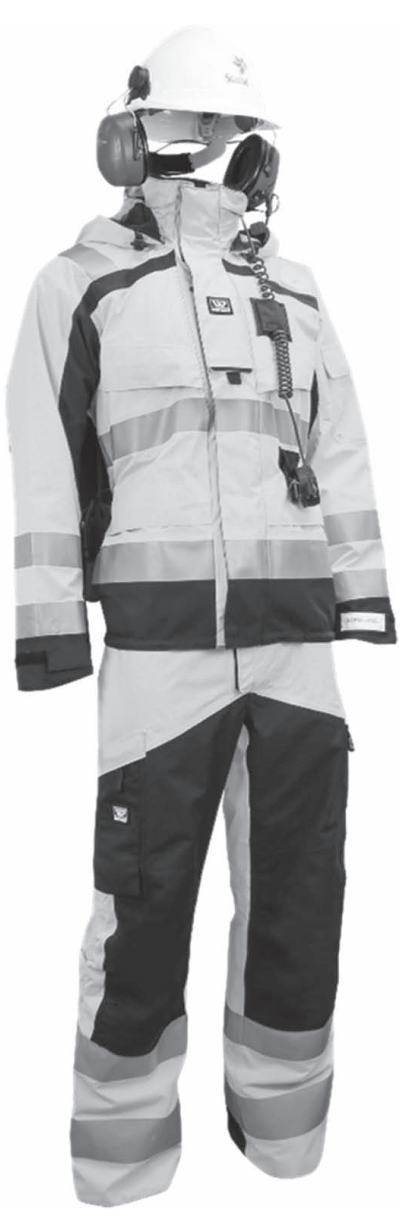

Fig. 1. The new outer layer jacket and pants developed in the innovation project.

the stages of 1) Establish insights of user needs and context of use, 2) Specify design objectives, 3) Design new solutions, and 4) Evaluation ${ }^{28)}$. Petroleum workers were involved throughout the design process; in establishing user insights, in concept development by participatory design, and in evaluating the design via field testing.

\section{Establish insights of user needs and context of use}

Detailed knowledge of user needs and the context of use was obtained during the first stage ${ }^{24)}$. It was established by i) interviews and observations of workers $(n=20)$ on board a platform, ii) complementary telephone interviews with relevant informants $(\mathrm{n}=10)$, and iii) the screening of stateof-the-art (SOTA) PPC (by retailer visits and internet and catalogue searches), extracting design requirements from relevant standards and regulations, and a literature review of cold-protective clothing and operation in cold conditions.

The R\&D team familiarized with the offshore work situation, and established user insight, during a four-d field- trip on board a drilling platform operating in the Barents Sea $\left(72^{\circ} \mathrm{N}\right)$. Several semi-structured group interviews were held with 20 workers operating in exposed areas on the platform. An interview guide was prepared, with questions based on tools for assessing and managing cold risk described in ISO $15743^{37)}$ and experiences from previously performed design projects related to PPC, to learn about currently used PPC, challenges related to operating in cold conditions and user needs related to PPC. The team also performed on-the-job observation of workers during their everyday work, in order to establish a better understanding and to identify latent user needs ${ }^{32}$. Ambient conditions, tasks, activity levels, pattern of movement, areas of wear and tear, the use of tools and other aspects relevant to the further design process was noted.

These insights were complemented with semi-structured telephone interviews with 10 informants with relevant work experiences from operating in cold conditions in the Barents Sea. These included petroleum workers, personnel safety representatives and representatives from the operating company's health, safety and work environment organisation (HSE). The same interview guide was applied in these telephone interviews.

2. and 3. Specify design objectives and design new solutions

User needs, key challenges and areas of improvement were identified in the insights stage, and the knowledge of these constituted the focus of the following design work. Two iterations of design and evaluation was completed in the project. The initial stage of concept development resulted in a design specification from which the first prototype could be produced, which was a new wind and waterproof outer layer garment including a PTFE membrane.

\section{Evaluation}

The evaluation stage involved both testing in the field and in cold climate chamber, both during the design process and at the end, to support concept development and document clothing properties. Informed consent was obtained from each subject and the ethics committee at the Norwegian Centre for Research Data approved the experiments.

Field testing by end-users in actual work situations was carried out to test the validity of the design assumptions and gather the user's experiences with the new clothing. PPC prototypes were distributed to end-users on two occasions, during both winters of the project period. The 
first prototype was tested by workers on board a drilling platform in the Barents Sea $\left(72^{\circ} \mathrm{N}\right)$. The R\&D team was unable to be present during the field test, so the platform's safety officer administered the recruitment of test persons and initiated the field-tests on board. Nine workers tested the prototype clothing over a period of four wk of normal work. After the test period, user experiences were registered and discussed via semi-structured group interviews by two video conferences and a face-to-face meeting. The users had received an interview guide together with the prototype at the start of the test in order to prepare them for the follow-up interviews. This interview guide builds on the one used in the insights stage, but asked more systematically about the worker's experiences with the new properties and performance of the prototypes. The R\&D team facilitated participatory design, and besides discussing their use experiences in detail, the users were invited to suggest further improvements. After the test period, the prototypes were collected to ascertain the state of the clothing regarding e.g. wear and tear, staining, shrinkage and discoloration. The user feedback in the interviews formed the basis for a new design iteration. A refined design specification was developed, from which a second prototype was produced for the second field test.

The second prototype, including a multi-layer clothing system with wool base layer, a wool-based mid-layer and two outer layer garments (a weatherproof outer layer including a PTFE membrane and an insulated work vest), was distributed the following winter to three installations; 1) a drilling platform operating in the Barents Sea $\left(72^{\circ} \mathrm{N}\right)$, 2) a floating production, storage and offloading unit (FPSO) operating in the Norwegian Sea $\left(66^{\circ} \mathrm{N}\right)$, and 3$)$ the liquid natural gas (LNG) production plant in Hammerfest $\left(71^{\circ} \mathrm{N}\right)$. Five to ten test subjects tested the prototype at each location during four wk of normal work. The second field test was performed and reviewed in the same way as the first. The user experiences were registered in semi-structured group interviews; one by telephone, one by video conference and one face-to-face meeting. The feedback from the second field test formed the basis for the final refinement of the design before manufacturing was initiated.

The evaluation stage also included human tests in cold climate chamber, performed in the SINTEF Work Physiology Laboratory. Two tests were performed; 1) the thermal protection of the PPC in current use compared to that provided by a wind and waterproof PPC (prototype 1) during simulated realistic work conditions $(n=6)$, and 2$)$ the thermal protection of the new PPC (prototype 2) during simulated work conditions at a wind-chill temperature
(WCT) of $-25^{\circ} \mathrm{C}(\mathrm{n}=6)$. The first test was performed to provide the user-centred design process with quantitative documentation to support the material selection. It was executed to compare the subjective user feedback from the first field test with quantitative measurements from the cold climate chamber regarding the use of wind and waterproof PPC. The air temperature (Ta) in the climatic chamber was $0 \pm 0.5^{\circ} \mathrm{C}$. The experimental protocol consisted of alternating work intensities, from low to moderate, and with or without wind exposure $(4.5 \mathrm{~m} / \mathrm{s})$. The subjects wore similar wool base layer, and only the outer-layer PPC was different. Skin temperatures, heat flux, heart rate, clothing humidity and thermal sensation were measured. The measurements of subjective responses when they wore a traditional cotton coverall was compared with when wind and waterproof outer-layer clothing was worn.

The second test evaluated the thermal protection of the new PPC under more extreme conditions. Although the WCT guidelines presented in ISO $11079^{38)}$ are designed with regards to risk of frostbite on unprotected skin, the petroleum industry utilize WCT as a general cold stress management tool. Six healthy male volunteers were included in the test, in WCT of $-25^{\circ} \mathrm{C}$ for a duration of $60 \mathrm{~min}$. The air temperature $(\mathrm{Ta})$ in the climatic chamber was $-20^{\circ} \mathrm{C}$ and the air velocity was $2.5 \mathrm{~m} / \mathrm{s}$. The test subjects wore the complete four-layer PPC ensemble, including wool base layers, wool mid-layer, wind and waterproof outer layer (jacket and trousers) and an insulated work vest. Skin temperatures, heat flux, heart rate, clothing humidity and thermal sensation were measured. The recommended maximal continuous duration of exposure in WCT of $-25^{\circ} \mathrm{C}$ is limited to $30 \mathrm{~min}^{38,39)}$.

Other methods used during the user-centred design process include calculations of insulation required $(\text { IREQ })^{38,40)}$ and measurements of thermal insulation by a thermal manikin ${ }^{41,42}$. IREQ was used to estimate the insulation required for relevant cold stress, activity levels and duration of cold exposure, based on the insights stage. A thermal manikin was used to measure the thermal insulation for different ensembles of the new multilayer PPC. The results of these methods provided input throughout the development process, but are not further described in this paper.

\section{Results}

Here we report on the key findings from accomplishing a user-centred design process to develop new PPC for offshore petroleum workers. These are listed and described 
below:

1) Knowledge of context of use provided useful insights for concept development

2) Providing users with an early prototype of the clothing was useful for participatory design

3) The users reported enhanced user satisfaction with the new PPC

4) Participatory design is challenging when remotely located users are involved

5) The user-centred design approach contributed to tailored design solutions

6) The evaluation stage supported the user-centred design process

\section{1) Knowledge of context of use provided useful insights for concept development}

The insights stage provided extensive knowledge of the context of use and gathered knowledge of user needs and preferences, ambient conditions, relevant PPC performance standards, ratings of current PPC and key challenges related to working in cold conditions. Mandatory requirements from standards and regulations provided guidance for concept development, and the review of SOTA clothing provided knowledge of typical properties of existing PPC for this application (e.g. applied materials, pocket configurations and functional solutions). Typical tasks include operating and maintaining drilling/lifting equipment, preparing and handling drill pipes, casings and tubes, and offloading supplies from supply vessels and moving them to storage areas. Based on the input from the users the R\&D team could identify the worker's key challenges related to working in cold conditions. These are elaborated below:

i) Extensive exposure to wind and external moisture: The users operate in open and semi-sheltered work areas, which involve periods of extensive exposure to wind and external moisture. They are exposed to external moisture from precipitation, but just as much from work situation characteristics. They frequently climb between items of equipment in narrow spaces, and changing weather and de-icing systems involve surfaces wet from melt water. Work also involves frequent use of high-pressure power washers. The PPC in current use, which include wool base layers and traditional cotton coveralls, provides poor wind and moisture protection, and users become cold and wet during work. The coverall soaks up moisture, which involves added weight, reduced comfort and accelerated cooling. Wind is regarded as a greater challenge than the cold. In windy conditions, the workers must put on addi- tional mid-layer clothing to keep warm, leading to bulky clothing ensembles. Many workers wear a disposable chemical suit outside the work coverall to compensate for the poor weather protection in current clothing. These have poor wear resistance and restrict access to pockets, tools and communication equipment. For these reasons, good weather protection represented an important area of improvement.

ii) Efficient temperature regulation: Overall, workers maintain high levels of activity during their work. They perform tasks that frequently alternate between low and moderate to high work intensities, and frequently move between indoor and outdoor work areas. In addition to mid-layer clothing, they have access to insulated work jackets and coveralls when increased thermal protection is needed, but they prefer not to use these because they are bulky, impair freedom of movement and quickly induce excessive sweating. They were regarded as too warm to move around in even at light to moderate work intensities. Most of these garments soak up moisture similarly to the work coveralls, which considerably increases their weight. Cold-protective clothing that would facilitate efficient temperature regulation according to changes in work intensities, ambient conditions and individual preferences was an important area of improvement.

iii) Thermal protection during stationary work: Outdoor work periods involving stationary work are regarded as the most challenging situation regarding cold exposure. These include crane operations, loading/unloading supply vessels and long-lasting trouble-shooting and repairs of equipment. The interviews indicated that these tasks may continue for as much as two $h$ of continuous effort.

iv) Maintaining unrestricted movement: Much of the work involved a wide range of body movements, including kneeling, bending, leaning on cold and hard surfaces, climbing in between equipment, in narrow spaces, in stairs and up in the derrick tower, often wearing a climbing harness and working with arms raised above the shoulders. Therefore, unrestricted movement was regarded as a key property in the PPC to maintain work performance and comfort.

\section{2) Providing users with an early prototype of the clothing was useful for participatory design}

The first iteration of design work produced a PPC prototype, based on the insights stage. Distributing a prototype at an early stage of the project proved successful with regards to user-involvement in the development process, and the prototype functioned as a natural starting point 
for discussion of further refinements of the design in the follow-up interviews. The users effectively participated by pointing out necessary improvements, and this comprehensive feedback enabled us to perform two iterations of design refinement. The concept development was driven by the iterations of user evaluation via field testing.

Rig worker: 'When the wrist adjustment is tightened the remaining flap is protruding. The Velcro is too long. Can this be adjusted? It should be several centimetres shorter'

3) The users reported enhanced user satisfaction with the new PPC

The user feedback following the field-tests indicated enhanced user satisfaction with the new PPC, compared to the clothing in current use, after following the usercentred approach. Overall, the users were pleased with the first prototype, and the group discussions in all of the three group meetings concluded that the new PPC represented an improvement. The improved protection from wind and external moisture was highly appreciated, and a collective feedback was that the prototype improved thermal comfort, reduced the need for mid-layer clothing, and enabled users to wear lighter, less bulky clothing ensembles. Disposable chemical suits were not used merely for weather protection. The first prototype introduced a two-part solution (jacket and trousers) to the users. This was preferred by most workers because it made it easier to regulate the wearers temperature for example when moving between indoor and outdoor working areas.

Rig worker: 'I think it was brilliant with a jacket and trousers solution. Then you can take of your jacket on your way into the breakroom, which makes it easier to adjust and ventilate the clothing'

The interviews following the first field test pointed out the direction for further design work. The users emphasized the need for several specific design improvements: 1) improve the fit for unrestricted movement, 2) provide knee protection from hard, cold and occasionally studded surfaces, 3) adjust the pocket configuration to improve usability with gloved hands, support work performance and provide practical storage of work gloves, 4) improve clothing ventilation and 5) provide solution that improves the compatibility with communication equipment.

The group discussions in all three group meetings following the second field test showed consensus about enhanced user satisfaction with the new PPC, and only minor design refinements were suggested. The users were pleased with the new design and expressed that it included relevant, attractive and practical functional solutions. They also reported of enhanced work comfort and performance, and the improved weather protection and ability to perform work in lighter and less bulky clothing ensembles were praised.

Rig worker: 'Now we have used only wool base layers underneath. That's enough to keep us comfortable inside this new outer layer clothing. That would have been far too cold when using the cotton coveralls. This is an important safety aspect; when you are cold and freezing at work you become distracted and lose focus'

\section{4) Participatory design is challenging when remotely located users are involved}

The target-users represent an especially inaccessible work group, which operate on-board remote offshore installations and follow a rotational work schedule of $14 \mathrm{~d}$ on, $28 \mathrm{~d}$ off. This represented a challenge with regards to involving the users in the design process. The interviews following the field tests were accomplished by telephone and video meetings, while the interview with the participants at the onshore LNG production plant was accomplished as a face-to-face meeting. The participants at all three locations had been able to test the clothing prototypes in similar ways, and the interviews followed the similar semi-structured plan of execution.

We experienced that the face-to-face meeting facilitated a higher level of user participation and input to the development process. Interacting in the same room allowed the users to be more actively involved, more specific in their feedback and more 'hands-on' when discussing refinements of the design. They could use the prototype more actively as a tool to enhance communication and understanding, and could introduce tools and PPE used during daily work to illustrate their suggestions. To a certain degree, this was achieved also during the video meeting, where users could indicate their suggestions on screen. On the other hand, the telephone interview reduced the output of the interview-session with regards to participatory design.

\section{5) The user-centred design approach contributed to tai- lored design solutions}

The user-centred approach contributed to several design solutions tailored to the specific workers. Two specific examples include a solution for improved compatibility with communication equipment and for more efficient handling of paperwork.

The workers carry a radio unit in a waist belt outside of 


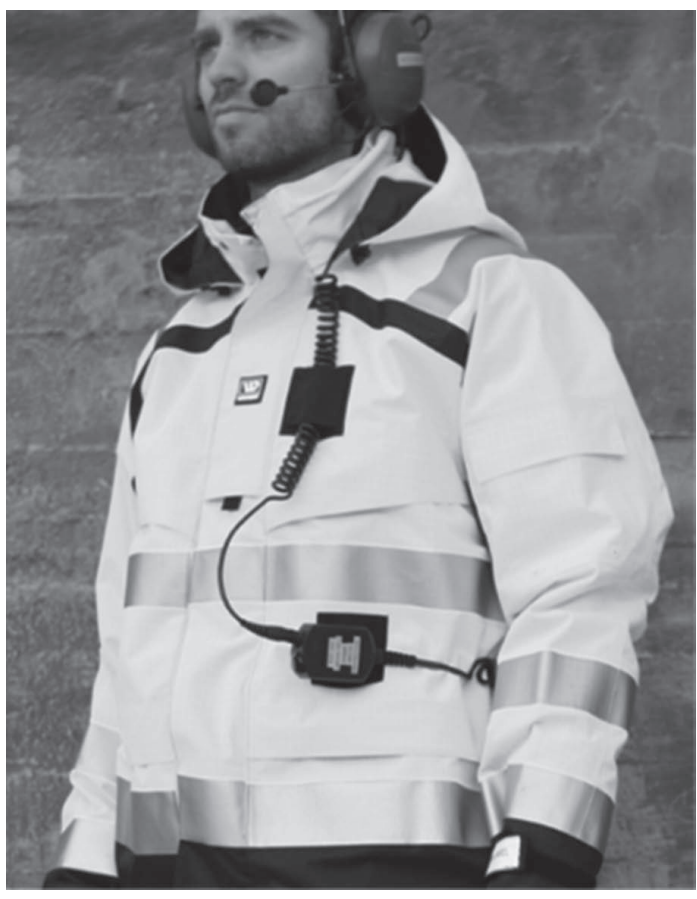

Fig. 2. The new jacket solution for cable management.

the work coveralls. Radio cables run freely from the radio unit to a push-to-talk unit (PTT), and then up to the hearing protectors mounted on the helmet. The PTT is attached with a clip to the front of the PPC anywhere the users can make it stick. The radio cables represent a risk of snagging and a source of irritation, and this issue was pointed out by several users following the first field test. When working in heights, a detachment of the radio cable involves a safety risk by loss of communication with the support crew on deck. Thus, a specific solution for cable management was developed (Fig. 2). Users pointed out practical positions for attachment of the PTT, based on considerations of easy-access and limited risk of snagging, and tailored patches dedicated for sturdy attachment of the PTT was incorporated in the design. The PTT can be attached at two alternative positions, and the patches are compatible with PTTs from different suppliers, which have the attachment clips oriented opposite ways. They also function as tunnels for the radio cable to keep it in place close to the body.

The users regularly carry with them different forms for taking notes and documentation. These typically need to be folded and tucked inside an undersized chest pocket of the coverall, a solution which was reported to be both impractical and challenging in moments of wind and precipitation. Thus, a napoleon chest pocket with an A4-paper sized zip opening was implemented in the design. In the followup interview, several users stated their appreciation for this pocket which allowed them to efficiently access or dump the forms without the need of folding/unfolding. This supported a more efficient and appropriate handling of paperwork during outdoor work.

\section{6) The evaluation stage supported the user-centred design process}

Different methods of evaluation were applied to provide useful input throughout the user-centred development process. The methods complemented one another and contributed to the design with regards to both performance and protection. Realistic test protocols for the cold climate chamber evaluations could be developed based on the insights stage.

Field testing represented a vital quality assurance of the effectiveness of the design and functional solutions, and the usability of these during daily work and in cold conditions, to attain a high level of performance, comfort and user satisfaction. The field tests were performed from an early stage, which made it possible to refine the design by two iterations of user feedback. They also provided feedback on the thermal performance during daily work, with regards to exposure protection and temperature regulation. Following the first field test, the users reported enhanced thermal comfort when wearing the PPC prototype. The results from the first cold chamber test supported the subjective user feedback from the field, and provided objective documentation of the positive effects of wearing PPC with improved wind and moisture protection. The higher air permeability of the cotton coveralls leads to increased heat loss and further reduced skin temperatures and thermal comfort. Material selection could be based on both subjective and objective information.

The second cold climate chamber test documented that the new PPC provided sufficient thermal protection, and maintained skin temperature and thermal comfort within acceptable limits ${ }^{38)}$, during the 60 min of simulated work in WCT of $-25^{\circ} \mathrm{C}$ (Fig. 3). Thermal sensation of the body was rated slightly cool within the first $20 \mathrm{~min}$ and slightly warm during the final part of the test. Skin temperatures dropped from $33^{\circ} \mathrm{C}$ to about $29^{\circ} \mathrm{C}$ during the first $40 \mathrm{~min}$ of the test, and increased up to $30^{\circ} \mathrm{C}$ during the final $20 \mathrm{~min}$.

The IREQ calculations provided useful input to the design of the clothing system with regards to suitable levels of insulation, and could be compared with results from the tests in the field and the cold climate chamber. The results from the thermal manikin testing demonstrated that the insulation value of new PPC system can be adjusted to variations in work intensity, ambient conditions and indi- 


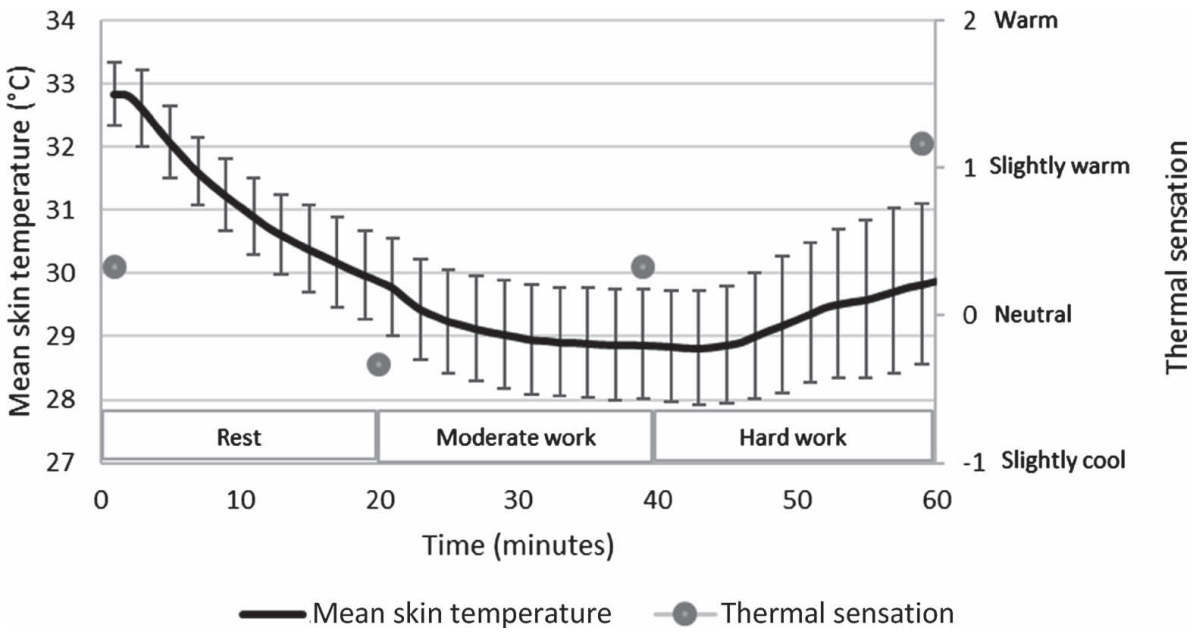

Fig. 3. Mean skin temperature and thermal sensation during various work intensities at WCT of $-25^{\circ} \mathrm{C}$ when wearing the new PPC. Data are presented as mean and SD for skin temperature and mean for thermal sensation. $(\mathrm{N}=6)$

Table 1. Insulation values (clo) from the thermal manikin tests of different ensembles of the new cold protective clothing system

\begin{tabular}{lcc}
\multicolumn{1}{c}{ Clothing ensemble } & $\begin{array}{c}\text { Total clothing } \\
\text { insulation }\left(I_{T}\right)\end{array}$ & $\begin{array}{c}\text { Basic clothing } \\
\text { insulation }\left(I_{c l}\right)\end{array}$ \\
\hline 2-layer ensemble (wool base layer, weatherproof outer layer) & 2.54 & 1.96 \\
3-layer ensemble (wool base layer, wool mid-layer, weatherproof outer layer) & 3.11 & 2.54 \\
4-layer ensemble (wool base layer, wool mid-layer, weatherproof outer layer, insulated work vest) & 3.58 & 3.00 \\
\hline
\end{tabular}

vidual preferences (Table 1). The insulated parka was not completed in time for the thermal manikin tests.

\section{Discussion}

The user-centred design process established comprehensive knowledge of user insights and the context of use, from which new and improved PPC for petroleum workers could be developed. As indicated by McCann ${ }^{29)}$, the user insight impacted on a breadth of design considerations regarding for example comfort, protection, durability, weight, ease of movement, level of insulation and functionality. The insights stage efficiently put the design process on track of key areas of improvement, and the user insight represented a considerable source to development of tailored functional solutions. The field-trip provided the R\&D team with a deep understanding of the work situation of the users. However, a visit to more than one platform would provide better insight into the considerable variations in context of use between individual platforms, including differences in e.g. tasks, activity levels, range of movement and level of weather protection.

The process demonstrated that it was valuable to pres- ent the end-users with an early clothing prototype. The initial design was based on the user insights, so feedback of improved user satisfaction, compared to the PPC in current use, was expected. Rather than presenting the users with the clothing prototype and inviting them to respond to the design directly, the users could establish use experiences from daily work before participating in refinement of the design. Such a sensitizing process is known to enhance the quality and quantity of contributions that participants make in sessions of participatory design ${ }^{43}$. Reviewing the prototype in detail enabled the users to be specific in their qualitative feedback, and they participated with confidence because most feedback could be substantiated in concrete use experiences from the field test. Our starting point was that a user-centred development process would enhance user satisfaction by contributing to reduce the detrimental effects of PPC. The user feedback collected from the second field test indicated a high level of user satisfaction after following this approach, compared to the PPC in current use. A key benefit of user-centred design is the iterations of design and evaluation, and two iterations based on user feedback were achieved. Qualitative feedback was emphasized throughout the project to provide basis for 
refinement of the design.

User-involvement was challenging due to the inaccessible character of the users. Participatory design was best achieved during face-to-face interviews, but also through video conference interviews. Users were recruited to field testing and interviews based on the ability to participate at the time of the different activities. An alternative approach is to establish a group of dedicated lead-users ${ }^{44)}$, which are experts in the details of the work situation, and who will follow and participate throughout concept development to ensure refinement of the design according to user needs. Sanders and Stappers ${ }^{45)}$ introduce various generative methods which can be used to involve users in the design process. Users can be involved in generative sessions, to inform designers in early stages of the development pro$\operatorname{cess}^{45,46)}$.

To identify the breadth of user needs, one should involve a range of users and stakeholders (e.g. representatives from manufacturing and departments of purchase, maintenance and HSE) which challenge the PPC in various ways and present various user needs based on e.g. occupation, area of operation, use of tools and individual preferences. If a limited number of users are involved in the design process, one must ensure to balance the impact of each individual on the clothing design, and consider the user input in relation to the context of use. When developing PPC for inaccessible work groups, one might consider alternative sources of user feedback. More accessible work groups, operating in comparable weather and work conditions, can be utilized to get hold of user feedback regarding for example thermal performance. Despite different work situations, these users can make useful contribution to the design process. Alternative work groups might include construction workers, energy workers and mine workers operating in cold conditions.

The conflicting interest of performance and protection has been a primary challenge during concept development. The PPC should enable good performance and thermal comfort during daily work in cold conditions, but at the same time provide the necessary thermal protection in the worst-case conditions which might be expected. The insights documented regular and considerable variations in both work intensity and ambient conditions throughout daily work. An adjustable multi-layer clothing system was necessary to provide good performance and comfort despite of variations in work intensity, ambient conditions and individual preferences. The thermal manikin tests indicated basic clothing insulation values $\left(\mathrm{I}_{\mathrm{cl}}\right)$ ranging from 1.96 to $3.00 \mathrm{Clo}$. The new PPC system also includes an insulated parka. It was not completed in time for the thermal manikin, but involves the option of an even greater clothing insulation value for use e.g. during stationary work. A holistic top-to-toe approach was adopted to ensure good interaction between the different garments. Documentation of the thermal performance of a clothing system, in a dynamic relationship with the wearer and shifting work conditions, represents a comprehensive task for the stage of evaluation. The cold chamber tests were performed in a dry, cold environment. Although the users experience periods of high work intensity and profound sweating, they are more likely to become wet from external moisture exposure. The dynamics of sweating and external moisture exposure when operating in cold and wet environments can be explored more comprehensively.

A five-level system has been proposed as a valid method for testing and development of PPC ${ }^{34,47)}$, and mixedmethods of field tests and cold chamber tests have been performed in the project. Fabrics were selected based on documented performance and protection properties. The tests provided a comprehensive evaluation of the new PPC including both performance and protection properties. Methods of evaluation was applied throughout concept development to provide useful input for decision support. Preliminary cold chamber tests can be utilized to provide the design process with useful indications of the effects of new design solutions, to ensure that the most promising designs are selected for further development. The tests should be directed towards the specified design objectives.

Controlled tests in the cold climate chamber proved especially important when developing PPC for use in new areas of operation, and to verify proper thermal protection in worst-case conditions and in line with industry guidelines. The field tests were performed under relevant cold conditions, but not representative of the conditions which might occur in the northern and eastern regions of the Barents Sea in the winter. During the project period, there were no platforms operating in these regions. The knowledge from the insights stage was utilized to create test protocols which simulate relevant climatic conditions and activity levels of the users. Based on the insights stage, relevant values of cold stress, activity levels and duration of cold exposure could be specified for the IREQ calculations. Suitable levels of insulation could be indicated, rather than designing PPC for eight $\mathrm{h}$ of continuous outdoor exposure, which is rarely the case for the end-users.

Collaboration in a multi-disciplinary R\&D team was useful when developing new PPC. The designers benefited from gaining overview of human physiological issues that 
impinge on the design of functional clothing, and obtained greater understanding of how new designs might influence thermal performance. It also facilitated the incorporation of the evaluation stage into the user-centred design process. Close collaboration with industrial partners provided insight into framework conditions related to manufacturing, standardization and operation. The current project focused explicitly on design of new PPC. A more comprehensive approach could focus on PPC in conjunction with complementary organizational guidelines to optimize recommended work and rewarming periods, shielding measures etc. A comprehensive clothing system, including more advanced PPC, entails the need for enhanced awareness, skill and training of the users to utilize and adjust the clothing properly.

\section{Conclusions}

The consensus from the group meetings following the field tests indicate that accomplishing a user-centred design process, taking into account user needs and involving the users throughout the design process, contributed to new cold-protective clothing with an improved level of user satisfaction and which include relevant, attractive and practical functional solutions. The established knowledge of user needs and context of use provided useful input to the design process and development of tailored design solutions. Providing the users with clothing prototypes was useful to achieve participatory design and iterations of design refinement.

The results of the final evaluation in the cold climate chamber indicated that the new cold-protective clothing provides sufficient thermal protection, and maintains thermal comfort within acceptable limits, during the $60 \mathrm{~min}$ of simulated work in $\mathrm{WCT}$ of $-25^{\circ} \mathrm{C}$. This resembles worstcase conditions which might occur in regions of the Barents Sea during the winter.

At the time of writing, the current innovation project has been completed and the new cold-protective clothing have been presented in the market for the Norwegian petroleum industry.

\section{Acknowledgement}

This innovation project ${ }^{48)}$ was carried out in collaboration with the industrial partners Wenaas Workwear, Statoil and Eni Norway. The project was partially financed by the Research Council of Norway.

\section{References}

1) The Goliat field. Available at: https:/www.statoil.com/en/ what-we-do/partner-operated-fields-in-norway/goliat.html. Accessed June 2017.

2) Goliat on stream. Available at: http://www.eninorge.com/ en/Field-development/Goliat/. Accessed June 2017.

3) International Organization for Standardization (2010) ISO19906: Petroleum and natural gas industries - Arctic offshore structures

4) NORSOK (2007) N-003 Actions and actions effects. 2007.

5) IPIECA/OGP (2008) Health aspects of work in extreme climates. A guide for oil and gas industry managers and supervisors, London.

6) Holmér I (2009) Evaluation of cold workplaces: an overview of standards for assessment of cold stress. Ind Health 47, 228-34. [Medline] [CrossRef]

7) Palinkas LA (2001) Mental and cognitive performance in the cold. Int J Circumpolar Health 60, 430-9. [Medline]

8) Oksa J (2002) Neuromuscular performance limitations in cold. Int J Circumpolar Health 61, 154-62. [Medline] [CrossRef]

9) Sormunen E, Remes J, Hassi J, Pienimäki T, Rintamäki H (2009) Factors associated with self-estimated work ability and musculoskeletal symptoms among male and female workers in cooled food-processing facilities. Ind Health 47, 271-82. [Medline] [CrossRef]

10) Mäkinen TM, Palinkas LA, Reeves DL, Pääkkönen $T$, Rintamäki H, Leppäluoto J, Hassi J (2006) Effect of repeated exposures to cold on cognitive performance in humans. Physiol Behav 87, 166-76. [Medline] [CrossRef]

11) Anttonen H, Pekkarinen A, Niskanen J (2009) Safety at work in cold environments and prevention of cold stress. Ind Health 47, 254-61. [Medline] [CrossRef]

12) Cheung SS, Lee JKW, Oksa J (2016) Thermal stress, human performance, and physical employment standards. Appl Physiol Nutr Metab 41 Suppl 2, S148-64. [Medline] [CrossRef]

13) Færevik H, Tjønnas MS, Heen S, Wiggen ON, Reinertsen RE (2011) Required clothing insulation and recommended outdoor work exposure time for petroleum workers in the Arctic, in International Conference on Environmental Ergonomics. Nafplio, Greece.

14) Barents2020 (2012) Assessment of international standards for safe exploration, production and transportation of oil and gas in the Barents Sea.

15) Dorman LE, Havenith G (2009) The effects of protective clothing on energy consumption during different activities. Eur J Appl Physiol 105, 463-70. [Medline] [CrossRef]

16) Duggan A (1988) Energy cost of stepping in protective clothing ensembles. Ergonomics 31, 3-11. [Medline] [CrossRef]

17) Jussila K, Valkama A, Remes J, Anttonen H, Peitso A (2010) The effect of cold protective clothing on comfort and perception of performance. Int J Occup Saf Ergon 16, 185 
97. [Medline] [CrossRef]

18) Rissanen S, Rintamäki H (1998) Effects of repeated exercise/rest sessions at -10 degrees $\mathrm{C}$ on skin and rectal temperatures in men wearing chemical protective clothing. Eur J Appl Physiol Occup Physiol 78, 560-4. [Medline] [CrossRef]

19) Dorman L, Havenith G, Bröde P, Candas V, den Hartog E, Holmer I, Meinander H, Nocker W, Richards M (2006) Modelling the metabolic effects of protective clothing, in European Conference on Protective Clothing (ECPC) and NOKOBETEF8. Gdynia, Poland.

20) Dolez PI, Vu-Khanh T (2009) Recent developments and needs in materials used for personal protective equipment and their testing. Int J Occup Saf Ergon 15, 347-62. [Medline] [CrossRef]

21) Bartels VT (2006) Physiological comfort of biofunctional textiles, in Biofunctional textiles and the skin, 51-66, Karger Publishers, Basel.

22) Rossi R (2009) Comfort and Thermoregulatory Requirements in Cold Weather Clothing, in Textiles for cold weather apparel, 3-18, Woodhead Publishing Ltd, Cambridge.

23) Holmér I (1989) Recent trends in clothing physiology. Scand J Work Environ Health 15 Suppl 1, 58-65. [Medline]

24) Bougourd J, McCann J (2009) Factors affecting the design of cold weather performance clothing, in Textiles for cold weather apparel, 152-195, Woodhead Publishing Ltd, UK.

25) Sanders EBN, Stappers PJ (2008) Co-creation and the new landscapes of design. CoDesign 4, 5-18. [CrossRef]

26) Steen M, Kuijt-Evers L, Klok J (2007) Early user involvement in research and design projects - A review of methods and practices, in 23rd EGOS Colloquium. Vienna, Austria.

27) Storholmen TCB, Naesgaard OP, Faerevik H, Reitan J, Holmen IM, Reinertsen RE (2012) Design for end-user acceptance: requirements for work clothing for fishermen in Mediterranean and northern fishing grounds. Int Marit Health 63, 32-9. [Medline]

28) International Organization for Standardization (2010) ISO9241-210: Ergonomics of human-system interaction, Part 210: Human-centred design for interactive systems.

29) McCann J (2009) End-user based design of innovative smart clothing, in Smart clothes and wearable technology, 45-69, Woodhead Publishing Ltd.

30) Black A (2006). User-centered-design: the basics of user-centred design. Available at: http://webarchive. nationalarchives.gov.uk/20080709144525/http://www. designcouncil.org.uk/en/About-Design/Design-Techniques/ User-centred-design-/. Accessed: June 2017.

31) Sanders EBN, Stappers PJ (2012) Convivial design toolbox: Generative research for the front end of design, 15-63, BIS, Amsterdam.

32) Sanders EBN (2002) From user-centered to participatory design approaches. Design and the Social Sciences: Making
Connections 1.

33) Uotila M, Mattila H, Hänninen O (2006) Methods and models for intelligent garment design, in Intelligent textiles and clothing, 5-18, Woodhead Publishing Ltd, Cambridge.

34) Parsons KC (2014) Human thermal environments: the effects of hot, moderate, and cold environments on human health, comfort, and performance, Third ed, CRC Press, Taylor \& Francis Group, Boca Raton. [CrossRef]

35) Sandsund M, Paasche A, Reinertsen RE (2001) Development and evaluation of a clothing system for offshore industry workers in cold environments, in Proceedings of the Australian Physiological and Pharmacological Society, 135.

36) Norman D (1988) The Design of Everyday Things, Basic Books, New York.

37) International Organization for Standardization (2008) ISO 15743: Ergonomics of the thermal environment-Cold workplaces - Risk assessment and management.

38) International Organization for Standardization (2007) ISO 11079: Ergonomics of the thermal environment. Determination and interpretation of cold stress when using requiered clothing insulation (IREQ) and local cooling effects.

39) NORSOK (2004) S-002 Working environment. 2004.

40) Holmér I (1988) Assessment of cold environments in terms of required insulation. Arctic Med Res 47 Suppl 1, 239-42. [Medline]

41) International Organization for Standardization (2004) ISO 15831: Clothing - Physiological effects - Measurements of thermal insulation by means of a thermal manikin.

42) British Standards Institution (2004) BS EN 342: Protective clothing. Ensembles and garments for protection against cold.

43) Sanders EBN, William CT (2002) Harnessing people's creativity: Ideation and expression through visual communication. Focus groups: Supporting effective product development 137.

44) Herstatt C, Von Hippel E (1992) From experience: Developing new product concepts via the lead user method: A case study in a "low-tech" field. J Prod Innov Manage 9, 213-21. [CrossRef]

45) Stappers PJ, Sanders EBN (2003) Generative tools for context mapping: tuning the tools, in Third International Conference on Design and Emotion, 85-89. Taylor \& Francis. [CrossRef]

46) Das A, Bøthun S, Reitan J, Dahl Y (2015) The Use of Generative Techniques in Co-design of mHealth Technology and Healthcare Services for COPD Patients, in International Conference of Design, User Experience and Usability, 587-95. Springer. [CrossRef]

47) Goldman RF, Kampmann B (2007) Handbook on clothing: biomedical effects of military clothing and equipment systems. Report NATO Research Study Group 7, 85-96.

48) Arctic Protection project webpage. Available at: http:// www.sintef.no/prosjekter/arctic-protection/. Accessed: May 2017. 